\title{
A UAV-based system for monitoring crop growth in wheat, barley and triticale phenotyping field trials
}

\author{
J.M. Peña ${ }^{1}$, F.J. Ostos-Garrido ${ }^{2}$, J. Torres-Sánchez ${ }^{2}$, F. Pistón ${ }^{2}$, A.I. de Castro ${ }^{2}$ \\ ${ }^{1}$ Institute of Agricultural Sciences - Spanish National Research Council (CSIC), C/ \\ Serrano 115-B, 28006 Madrid, Spain; ${ }^{2}$ Institute for Sustainable Agriculture - Spanish \\ National Research Council (CSIC), Avda. Menéndez Pidal s/n, 14004 Córdoba, Spain \\ jmpena@ica.csic.es
}

\begin{abstract}
This research evaluated the capability of an unmanned aerial vehicle (UAVs) -based system to monitor the plant heights of several wheat, barley and triticale field trials over time, by applying a customised object-based image analysis algorithm to the digital surface models created with the structure-from-motion technique. Comparisons between UAV-based and ground-based measurements over time reported an overall coefficient of determination $\left(\mathrm{R}^{2}\right)$ of 0.917 and an average root mean square (RMS) error of $0.10 \mathrm{~m}$. With a target of field phenotyping, a ranking of genotypes in term of plant heights and crop growth was accurately provided, which can facilitate the decision making process in cereal breeding programs.
\end{abstract}

Keywords: 3D digital surface model (DSM), plant height, remote sensing, object-based image analysis, cereal breeding program.

\section{Introduction}

Research on crop production is based to a certain extent on the analysis of the genotypephenotype relationships. While genotyping tools have made great progress in the last 20 years and have led to a better understanding of the plant genome, the phenotyping tools have not been able to meet the needs of high-performance, low-cost and non-destructive plant data collection and analysis (Araus \& Cairns, 2014). However, in recent years, new high-throughput phenotyping platforms are undergoing a rapid evolution that could significantly improve understanding between the association between genes and phenotype in the actual field conditions, including both on-ground platforms (Busemeyer et al., 2013) and aerial vehicles (Shi et al., 2016). Of all systems, unmanned aerial vehicles (UAVs) are taking relevance as a tool for phenotyping because of some advantages compared to other platforms (Yang et al., 2017). UAVs are a low-cost and reliable platform for taking frequent remote images that allow observation of the variation of plant trials over crop development (Torres-Sánchez et al., 2014). Furthermore, the capacities of the UAV to use a wide range of sensors, to operate at low flight altitude and to capture many consecutive images with high overlaps provide high-resolution spatial, spectral and three-dimension (3D) information of the studied plants. 3D data is obtained from the digital surface model (DSM) created by applying the structure-from-motion technique (Nex \& Remondino, 2014) and, as a result of this process, the physical and morphological characteristics of the observed plants or trees can be potentially quantified (JiménezBrenes et al., 2017; Moeckel et al., 2018). In the specific case of winter cereals, this technology has been applied for assessing plant height in barley (Bendig et al., 2014) and sorghum (Watanabe et al., 2017) and growth status in winter wheat (Du \& Noguchi, 
2017), but to authors' knowledge, there are no applications that assess its performance to monitor an experiment of multiple varieties of cereals with diverse phenotypic characteristics. In this work, the field trial of a breeding program designed to determine lignocellulosic bioethanol potential in cereals, in which it is essential to determine plant growth, was used to assess the capability of a UAV-based system to determine the height of the plants over time.

\section{Materials and methods}

A field trial with sixty-six accessions belonging to the species Hordeum vulgare (barley, 21 accessions), Triticum aestivum (bread wheat, 24 accessions), Triticum durum (durum wheat, 11 accessions) and $x$ Triticosecale (triticale, a hybrid of wheat and rye, 10 accessions) was established at the experimental station of the Institute for Sustainable Agriculture Center in Cordoba, Spain (coordinates 37.859 N, 4.796 W, datum WGS84). The experiment was sown on $15^{\text {th }}$ November 2013 following a completely randomized block design with three replications. Each block counted in 78 plots distributed in ten rows, with inter-plot distance of $0.30 \mathrm{~m}$ and inter-row distance of $0.50 \mathrm{~m}$. Each plot included four plants at approximately $0.15 \mathrm{~m}$ apart. A quadrocopter UAV model md41000 (microdrones $\mathrm{GmbH}$, Siegen, Germany) was used to collect the multi-temporal set of aerial images by using a still point-and-shoot visible-range camera, model Olympus PEN E-PM1 (Olympus Corporation, Tokyo, Japan) (Figure 1). The camera acquired 12megapixel images in red, green and blue (RGB) bands at $14 \mathrm{~mm}$ focal length. The UAV route was configured for flight at $3 \mathrm{~m} / \mathrm{s}$ and at $10 \mathrm{~m}$ flight altitude over the ground, and for taking down-facing photos at an interval of $1 \mathrm{~s}$ to achieve a side overlap of $60 \%$ and a forward overlap of $90 \%$. At this flight altitude, the spatial resolution of the RGB images was $3.81 \mathrm{~mm} /$ pixel of ground sampling distance. The UAV system collected the remote images on seven different dates: 1) 17 February (94 days after sowing, DAS), 2) 27 February (104 DAS), 3) 14 March (119 DAS), 4) 25 March (130 DAS), 5) 7 April (143 DAS), 6) 25 April (161 DAS), and 7) 9 May (175 DAS). The set of UAV images were processed to generate the ortho-mosaics of the experimental field at each study date (Figure 2). Additionally, the remote images were also used to build the digital surface model (DSM) of the field by applying the structure-from-motion technique (Jay et al., 2015). The DSM is a 3D polygon mesh that reflects the irregular geometry of the ground and contains information of the plant heights (Figure 3). Agisoft PhotoScan Professional software (Agisoft LLC, St. Petersburg, Russia) was used to generate these geo-spatial products. 


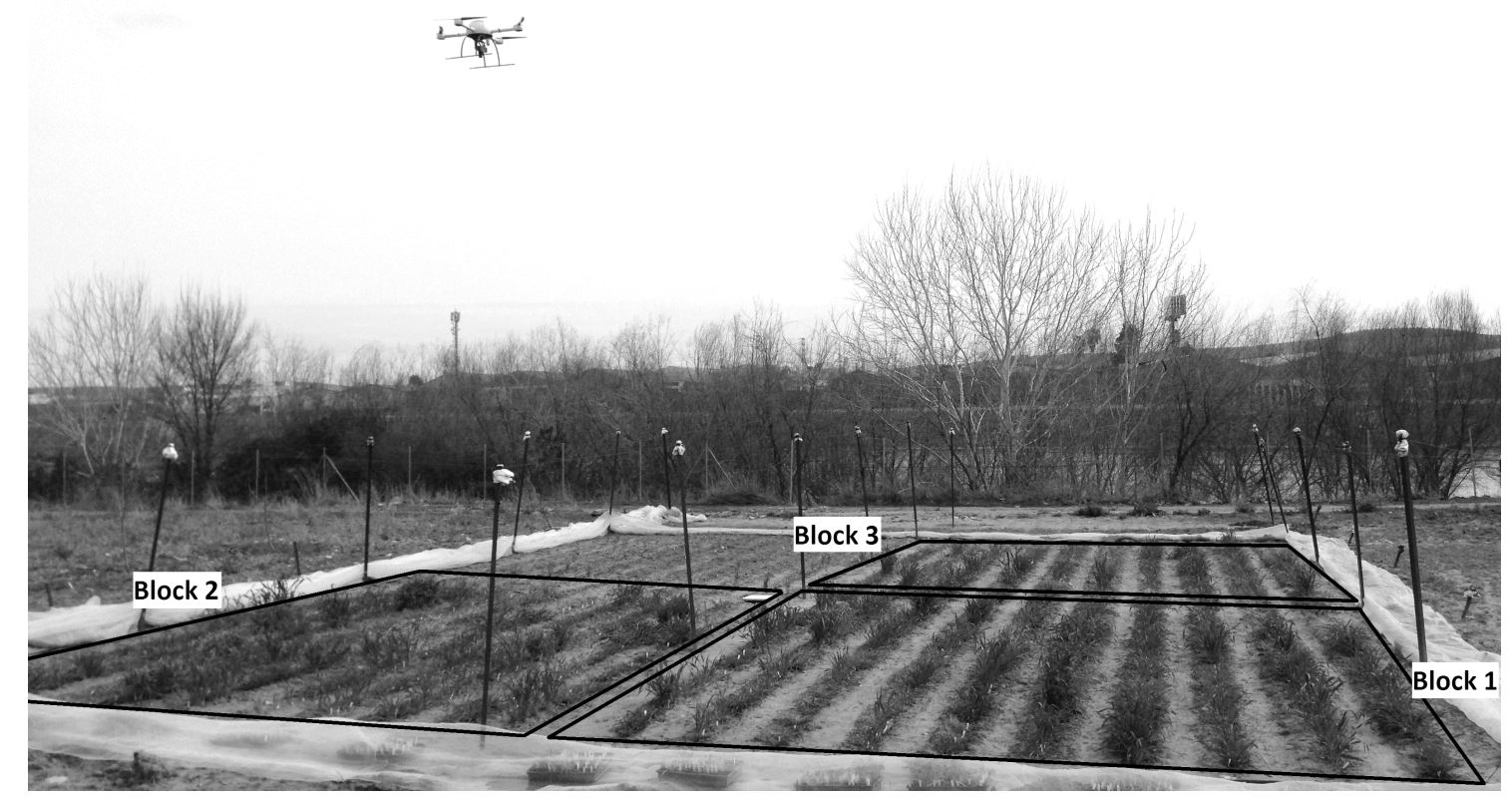

Figure 1. The UAV with the RGB camera flying over the experimental field at $10 \mathrm{~m}$ altitude in the date 1 (94 DAS).

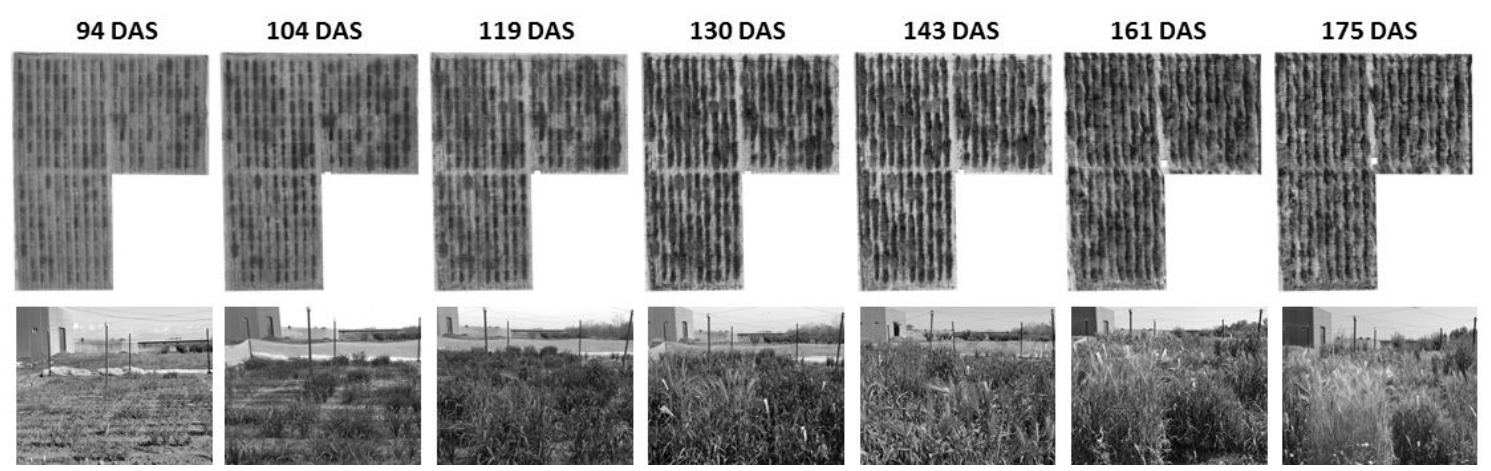

Figure 2. Aerial ortho-mosaicked images (in the top) and on-ground pictures of the experiment (in the bottom) at each study date. DAS: days after sowing.

The ortho-mosaicked images enabled visual identification of each one of the 234 trial plots, which were manually defined over the image and saved as a vector file. Then, a customized algorithm was created with the eCognition Developer software (Trimble Geospatial, Munich, Germany) to analyze the images and DSMs of each studied date by using an object-based approach after image segmentation (Blaschke et al., 2014). The algorithm was specifically programmed to run in a fully automatic manner without the need for user intervention, and with the ability to sequentially discriminate the vegetation fraction of every trial plot over time by applying the Otsu thresholding method described in Torres-Sánchez et al. (2015a). Once the crop objects were classified in each plot, the algorithm computed the central co-ordinates, the crop height and the relative position of every plot within the experiment design. The height of every crop object was obtained by comparing its maximum DSM value to the average DSM values of the surrounding bare soil objects. Finally, the customized algorithm automatically exported all the trial plot data as a table file (e.g., CSV or ASCII format) for further descriptive and statistical analysis. Data analysis was conducted with the statistical software JMP version 10 
software (SAS Institute Inc., Cary, NC, USA). Performance of the UAV-based phenotyping system was evaluated by comparing UAV-based and manual on-ground measurements over time, and thus determining the accuracy of the plant height estimations. The actual plant heights were manually measured on-ground with a tape measure over an aluminum bar at the same dates of the UAV flights. Plant height values were averaged for each trial plot.

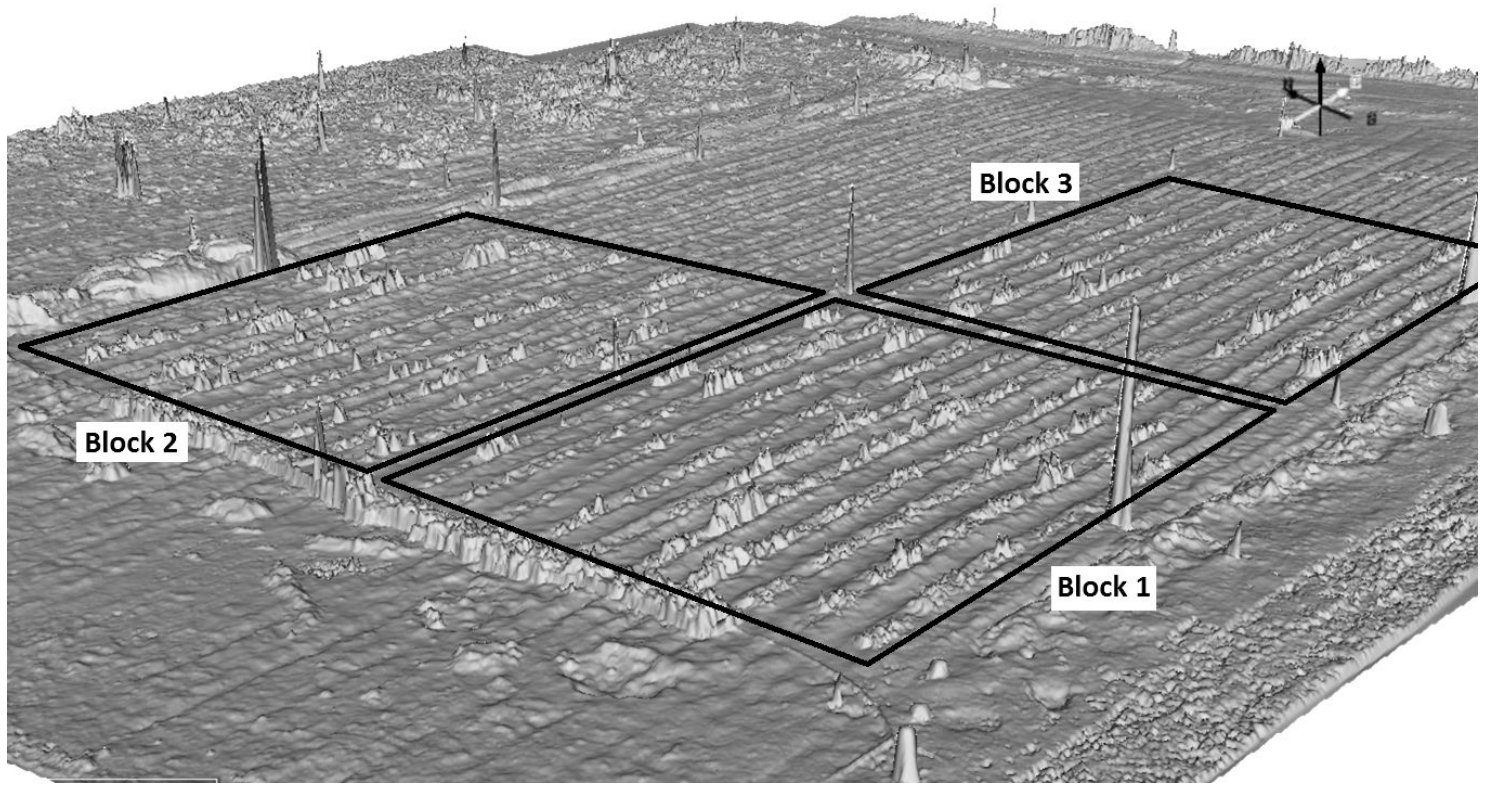

Figure 3. The Digital Surface Model (DSM) of the experimental field with 3D information of the overflown area in the date 1 (1 $7^{\text {th }}$ February).

\section{Results and Discussion}

Given the multitude of screened genotypes, many different phenotypes were observed in the study trial plots in terms of plant heights. The averaged plant heights collected on ground through the crop development ranked from minimum values of $0.38-0.40 \mathrm{~m}$ in the cases of the $H$. vulgare CP20 (Franka), the T. durum TP23 (Avalon) and the $T$. aestivum TP27 (Renan) genotypes, to maximum values of $0.92-0.99 \mathrm{~m}$ in the cases of the $x$ Triticosecale TS58 (Wapiti) and TS78 (Juanillo 95) and the T. durum TP20 (Rugby) genotypes. At the level of plant species, averaged heights of $T$. aestivum and $x$ Triticosecale $(0.62 \mathrm{~m}$ and $0.81 \mathrm{~m}$, respectively) were significantly smaller and higher, respectively, than the other species, while $H$. vulgare and $T$. durum did not show significant differences in averaged plant heights $(0.66 \mathrm{~m}$ and $0.70 \mathrm{~m}$, respectively).

The UAV-based phenotyping system computed the plant heights of every trial plot over time (Figure 4a). The height data were automatically retrieved from the DSMs created with the RGB images collected at each one of the seven UAV flights and applying the customized OBIA procedure developed in this investigation. The system measured a range of values between $0.04 \mathrm{~m}$ in the first date to $1.63 \mathrm{~m}$ in the last date. In addition, three different growth patterns were also detected (Figure $4 \mathrm{~b}$ ). The plants were identified as prostrate, semi-erect and erect during the tillering stage, and as semi-erect and erect at maturity. The accuracy of the estimates was evaluated by direct comparison with onground manual measurements (Figure 5). The UAV-based system under-estimated the 
ground-true measurements in most cases, computing values between $27 \%$ (date 1, 94 DAS) and 6\% (date 7, 175 DAS) lower than the real plant heights on average. Despite these under-estimates, high correlations were determined between UAV-based and ground-based measurements over time, reporting a global $\mathrm{R}^{2}$ of 0.917 and an average RMS of $0.10 \mathrm{~m}$. Specifically for each studied date, the best estimates were obtained on the date 3 (119 DAS), with a $\mathrm{R}^{2}$ of 0.894 and RMS of $0.05 \mathrm{~m}$, and the lowest determinations corresponded to the date 6 (161 DAS), with a $\mathrm{R}^{2}$ of 0.615 and RMS of $0.13 \mathrm{~m}$.

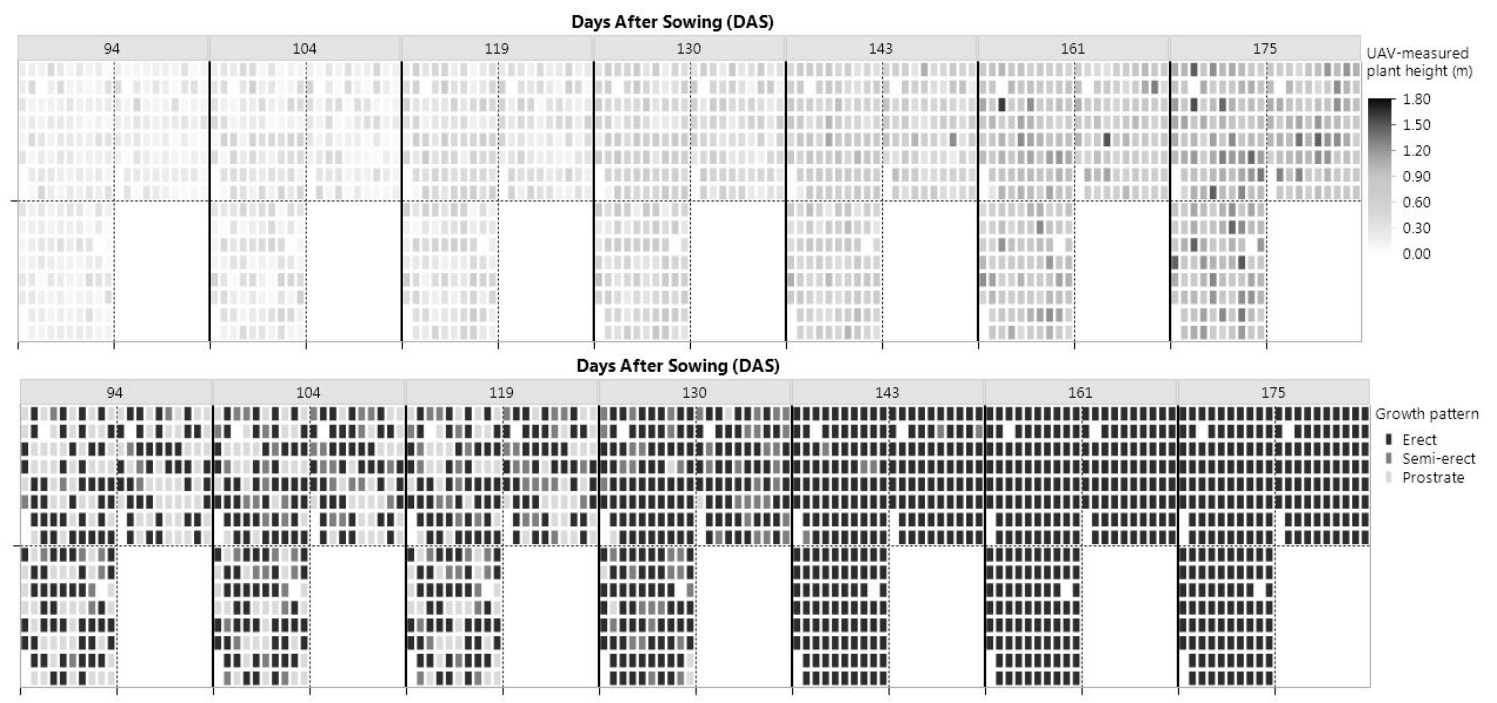

Figure 4. Plant variability measured by the UAV-based phenotyping system over time: a) plant heights, and b) growth pattern.

The UAV-based measurements were smaller than the ones manually taken on the ground. The UAV-based system computed the plant heights from the DSM created after combining numerous overlapped remote images, which usually lacks the precision to detect higher parts of the plants such as the spikes, which are observed during manual onground measurements. In addition, on-ground measurements are usually an average value of the maximum height of the plants, which is a subjective measure and depends on the experimenter. The under-estimates reported in the investigation were in line with the ones obtained in Bendig et al. (2014), who obtained a coefficient of determination of 0.92 in barley fields by using a UAV-based RGB imaging platform, and slightly lower than in Ehlert et al. (2008), who obtained coefficients of determination of 0.93 to 0.99 in winter rape, rye and wheat by using a ground based non-destructive laser rangefinder. In addition, Busemeyer et al. (2013) reported coefficients of determination of 0.97 and 0.92 in triticale by using a ground-based multi-sensor platform and a UAV-based system, respectively. This degree of under-estimation was also reported in previous case studies in several tree crops with larger dimensions such as vineyard (de Castro et al., 2018), olive trees (Torres-Sánchez et al., 2015b), poplar (Peña et al., 2018) and almond trees (Torres-Sánchez et al., 2018). 


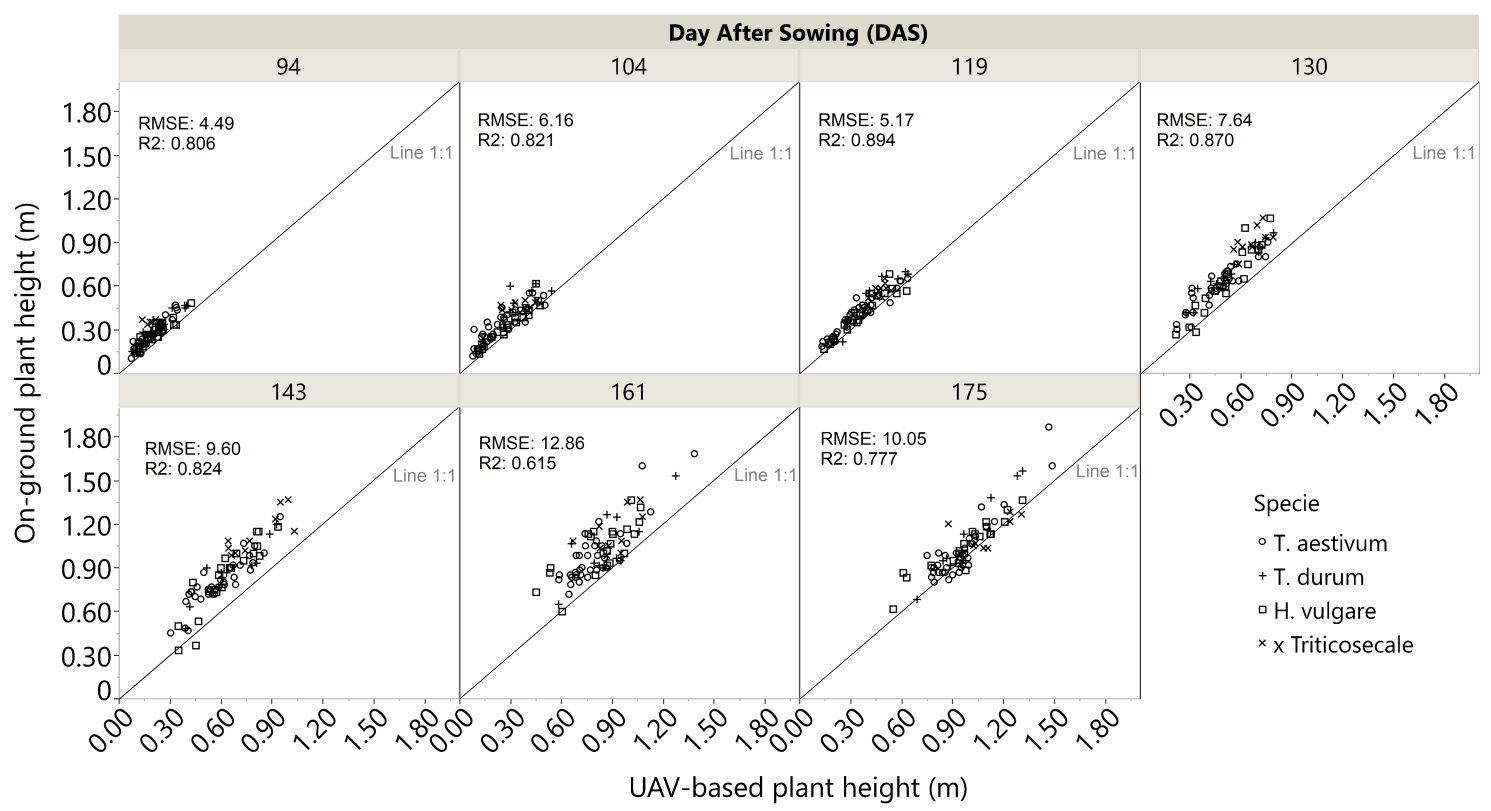

Figure 5. UAV-based estimated height $v s$. observed height as affected by study date.

\section{Conclusions}

The system computed the plant heights of 234 trial plots at seven different dates over crop development with high accuracy, which can drastically reduce the time needed for manual on-ground measurements. Consequently, differences of plant heights among numerous genotypes of triticale, wheat and barley species were reported, which provides useful nondestructive information to predict crop growth and crop production as a valuable resource for investigations in cereal breeding programs.

\section{Acknowledgements}

This research was partly financed by the AGL2017-83325-C4 and the AGL2011-22596 Projects (Spanish Ministry of Economy, Industry and Competitiveness - MINECO, and FEDER funds). Research of Dr. Peña, Mr. Ostos-Garrido and Dr. de Castro was supported by the Ramon y Cajal (RYC-2013-14874), FPI (grant BES-2012-457 052455) and the Juan de la Cierva (IJCI-2015-24811) Programs of the Spanish MINECO funds, respectively. We thank Tadeo Bellot for his help in field and laboratory work.

\section{References}

Araus, J.L., Cairns, J.E. 2014. Field high-throughput phenotyping: the new crop breeding frontier. Trends in Plant Science, 19, 52-61. https://doi.org/10.1016/j.tplants.2013.09.008

Bendig, J., Bolten, A., Bennertz, S., Broscheit, J., Eichfuss, S., Bareth, G. 2014. Estimating Biomass of Barley Using Crop Surface Models (CSMs) Derived from UAV-Based RGB Imaging. Remote Sensing, 6, 10395-10412. https://doi.org/10.3390/rs61110395 
Blaschke, T., Hay, G.J., Kelly, M., Lang, S., Hofmann, P., Addink, E., et al. 2014. Geographic Object-Based Image Analysis - Towards a new paradigm. ISPRS Journal of Photogrammetry and Remote Sensing, 87, 180-191. https://doi.org/10.1016/j.isprsjprs.2013.09.014

Busemeyer, L., Mentrup, D., Möller, K., Wunder, E., Alheit, K., Hahn, V., et al. 2013. BreedVision - A Multi-Sensor Platform for Non-Destructive Field-Based Phenotyping in Plant Breeding. Sensors, 13, 2830-2847. https://doi.org/10.3390/s130302830

de Castro, A.I., Jiménez-Brenes, F.M., Torres-Sánchez, J., Peña, J.M., Borra-Serrano, I., López-Granados, F., 2018. 3-D Characterization of Vineyards Using a Novel UAV Imagery-Based OBIA Procedure for Precision Viticulture Applications. Remote Sensing, 10(4), 584. https://doi.org/10.3390/rs10040584

Du, M., Noguchi, N., 2017. Monitoring of Wheat Growth Status and Mapping of Wheat Yield's within-Field Spatial Variations Using Color Images Acquired from UAVcamera System. Remote Sensing, 9(3), 289. https://doi.org/10.3390/rs9030289

Ehlert, D., Horn, H.-J., Adamek, R., 2008. Measuring crop biomass density by laser triangulation. Computers and Electronics in Agriculture, 61, 117-125. https://doi.org/10.1016/j.compag.2007.09.013

Jay, S., Rabatel, G., Hadoux, X., Moura, D., Gorretta, N., 2015. In-field crop row phenotyping from 3D modeling performed using Structure from Motion. Computers and Electronics in Agriculture, 110, 70-77. https://doi.org/10.1016/j.compag.2014.09.021

Jiménez-Brenes, F.M., López-Granados, F., de Castro, A.I., Torres-Sánchez, J., Serrano, N., Peña, J.M., 2017. Quantifying pruning impacts on olive tree architecture and annual canopy growth by using UAV-based 3D modelling. Plant Methods, 13, 55. https://doi.org/10.1186/s13007-017-0205-3

Moeckel, T., Dayananda, S., Nidamanuri, R.R., Nautiyal, S., Hanumaiah, N., Buerkert, A., et al. 2018. Estimation of Vegetable Crop Parameter by Multi-temporal UAVBorne Images. Remote Sensing, 10(5), 805. https://doi.org/10.3390/rs10050805

Nex, F., Remondino, F., 2014. UAV for 3D mapping applications: a review. Applied Geomatics, 6, 1-15. https://doi.org/10.1007/s12518-013-0120-x

Peña, J.M., de Castro, A.I., Torres-Sánchez, J., Andújar, D., Martín, C.S., Dorado, J., et al. 2018. Estimating tree height and biomass of a poplar plantation with imagebased UAV technology. AIMS Agriculture and Food, 3, 313-326. https://doi.org/10.3934/agrfood.2018.3.313

Shi, Y., Thomasson, J.A., Murray, S.C., Pugh, N.A., Rooney, W.L., Shafian, S. et al. 2016. Unmanned Aerial Vehicles for High-Throughput Phenotyping and Agronomic Research. PLOS ONE, 11, e0159781. https://doi.org/10.1371/journal.pone.0159781

Torres-Sánchez, J., de Castro, A.I., Peña, J.M., Jiménez-Brenes, F.M., Arquero, O., Lovera, M., et al. 2018. Mapping the 3D structure of almond trees using UAV acquired photogrammetric point clouds and object-based image analysis. Biosystems $\quad$ Engineering, 176, 172-184. https://doi.org/10.1016/j.biosystemseng.2018.10.018

Torres-Sánchez, J., López-Granados, F., Peña, J.M., 2015a. An automatic object-based method for optimal thresholding in UAV images: Application for vegetation detection in herbaceous crops. Computers and Electronics in Agriculture, 114, 43-52. https://doi.org/10.1016/j.compag.2015.03.019 
Torres-Sánchez, J., López-Granados, F., Serrano, N., Arquero, O., Peña, J.M., 2015b. High-Throughput 3-D Monitoring of Agricultural-Tree Plantations with Unmanned Aerial Vehicle (UAV) Technology. PLOS ONE, 10, e0130479. https://doi.org/10.1371/journal.pone.0130479

Torres-Sánchez, J., Peña, J.M., de Castro, A.I., López-Granados, F., 2014. Multitemporal mapping of the vegetation fraction in early-season wheat fields using images from UAV. Computers and Electronics in Agriculture, 103, 104-113. https://doi.org/10.1016/j.compag.2014.02.009

Watanabe, K., Guo, W., Arai, K., Takanashi, H., Kajiya-Kanegae, H., Kobayashi, M., et al. 2017. High-Throughput Phenotyping of Sorghum Plant Height Using an Unmanned Aerial Vehicle and Its Application to Genomic Prediction Modeling. Frontiers in Plant Science, 8: 421. https://doi.org/10.3389/fpls.2017.00421

Yang, G., Liu, J., Zhao, C., Li, Z., Huang, Y., Yu, H., et al. 2017. Unmanned Aerial Vehicle Remote Sensing for Field-Based Crop Phenotyping: Current Status and Perspectives. Frontiers in Plant Science, 8: 1111. https://doi.org/10.3389/fpls.2017.01111 